\title{
CHARACTERISTIC OF DROUGHT AND FLOOD IN THE DIAN-QIAN-GUI KARST AREAS BASED ON TRMM-Z INDEX
}

\author{
Yongfeng Wang ${ }^{1,2,{ }^{*}}$, Lisi Liang ${ }^{1}$, Juanli Jing ${ }^{1,2}$, Fulin Luo ${ }^{1}$, Anna Wang ${ }^{1}$ \\ ${ }^{1}$ College of Geomatics and Geo-information, Guilin University of Technology, Guilin 541004, China \\ ${ }^{2}$ Guangxi Key Laboratory of Spatial Information and Geomatics, Guilin 541004, China
}

KEY WORDS: TRMM 3B43; the Dian-Qian-Gui Karst Areas; Z index

\begin{abstract}
:
In order to study the spatial and temporal variation of characteristics of drought and flood in Dian-Qian-Gui Karst Areas of China, TRMM 3B43 precipitation data from 1998 to 2017 and 72 rain gauge station data from 1998 to 2012 were used to verify the TRMM 3B43 data on monthly scale by correlation coefficient and relative deviation. The TRMM-Z index was taken as an index of drought and flood to quantitatively analyze the drought and flood characteristics. The results show that: (1) there was a significant positive correlation between TRMM 3B43 precipitation data and the measured data of meteorological stations on the monthly scale, with a correlation coefficient of 0.92 , passing the significance test of 0.01 level. The calculated result of relative Bias is -0.058 , indicating that TRMM 3B43 precipitation is slightly higher than the actual precipitation. (2) From 1998 to 2017, the TRMM-Z index in the research area fluctuated between -1.160 and 1.678, among which the $\mathrm{Z}$ index in July 1999 reached the maximum value of 1.678 , and in February 2010 the $\mathrm{Z}$ index reached the minimum value of -1.160 . (3) During the past 20 years, the flood months in the study areas were 47 months, accounting for $19.58 \%$ of the study time, and 40 months were drought months, accounting for $16.67 \%$ of the study time. Floods mainly occurred in the summer with abundant rainfall, while droughts mainly occurred in the winter with less rainfall. (4) Taking 2008-2009 as typical representative of drought and flood, the spatial variation of drought and flood were researched.
\end{abstract}

\footnotetext{
*Corresponding author: Yongfeng Wang, Email:117232315@qq.com
} 


\section{INTRODUCTION}

Drought is one of the most serious natural disasters in the world. It has become a serious problem that endangers the living environment of human beings, and has been widely concerned by domestic and overseas scholars. China is one of the country with frequent drought disasters, especially in Southwest China, due to special geological and ecological environment, typical climate and varied vegetation types. In recent years, Southwest China has experienced frequent unusual drought events. For instance, severe drought happened in five province with Yunnan and Guizhou as the center from the autumn of 2009 to the ensuing spring of 2010 , causing about 21 million people were short of drinking water and the economic losses reached nearly US\$30-billion (Yang et al., 2012). Therefore, drought events and the evolution characteristic in Southwest China were payed much attention.

Southwest Karst areas has greatly influenced by monsoon climate, and complex topology, varied vegetation types, which made severe drought and flood occurred frequently. Some scholars analyzed the variation characteristics of drought in different scales based on meteorological stations (He et al., 2011, Yang et al., 2015). The trend of wet and dry climatic conditions in the karst area of Southwest China had been discussed also. (Liu et al., 2014). Drought index had been used to detect drought event in Southwest China, such as the standardized precipitation evapotranspiration index (SPI) (Huang et al., 2015), the standardized precipitation evapotranspiration index (SPEI) (Li et al., 2015, Wang et al., 2017), composite drought index (CI) (Li et al., 2014). With the development of remote sensing technology, many surface parameters could be inversed from multi-source satellite data. The cause of continuous drought had been analyzed in Southwest China from 2009 to 2010 by using ERA-40 reanalysis data and SST data (Huang et al., 2012). In addition, synthesized drought index, such as OMDI (optimized meteorological drought index) and the OVDI (optimized vegetation drought index) were proposed to monitor drought event in Southwest China (Hao et al., 2015). To improve drought monitor accuracy, parameters except precipitation, temperature, had been introduced to construct comprehensive drought index, such as soil moisture and runoff data, which could analyze the relationships among meteorological, agricultural, and hydrological droughts (Wu et al., 2016). And multiple drought indicators including SPI (Standardized Precipitation Index), ESI (Evaporative Stress Index), ETI (Evapotranspiration Index) and TWSC (Terrestrial Water Storage Changes) were used based on MODIS ET, GRACE datasets, and climate datasets (He et al., 2018).
From the above mentioned, there had been a lot of discussion about drought events in Southwest China, yet little attention had been payed to the evolution of flood. Furthermore, Tropical Rainfall Measuring Mission (TRMM) precipitation data used for regional analysis of drought and flood was still rare. Therefore, the drought and flood evolution characteristic in Southwest karst areas had been studied by constructing the $\mathrm{Z}$ index based on monthly TRMM 3B43 data from January 1998 to December 2017.

\section{RESEARCH AREA AND DATA SOURCES}

\subsection{Study Area}

Dian-Qian-Gui Karst Areas are mainly distributed in Yunnan, Guizhou and Guangxi of China, covering an area of $3.21 \times 105 \mathrm{~km}^{2}$, accounting for $23.4 \%$ of total karst area in China, and $39.7 \%$ of the total area of the three provinces. The terrain of the study area is high in the west and low in the east, and the karst geomorphology are complex and diverse, mainly composed of peak cluster depressions, peak forest plains, karst hill, karst valley et al. It belongs to the tropical and subtropical monsoon climate zone, and seasonal and regional differences of precipitation are obvious. The annual average temperature and precipitation are generally decreasing from southeast to northwest. The large area of carbonate rock is exposed, the soil is barren and the soil erosion is serious. The water resources are abundant, rivers and canyons are widespread. There is double hydrogeological structure between the surface and underground. The ecological environment is fragile, and the contradiction between population, resources and environment is prominent. It is a sensitive area of global change.

\subsection{TRMM 3B43 Data}

Tropical Rainfall Measuring Mission (TRMM) satellite data was successfully launched on November 27, 1997, and developed jointly by the National Aeronautical and Space Administration (NASA) of the United States and the National Space Development Agency (NASDA) of Japan, which is specially used to quantitatively measure tropical and subtropical rainfall. TRMM 3B43 data is the TRMM satellite version 7 , grade 3 product. The data coverage range is between $50^{\circ}$ south and north latitude, and the spatial resolution is $0.25^{\circ} \times 0.25^{\circ}$. In this paper, the TRMM $3 \mathrm{~B} 43$ data from the January 1998 to the December 2017 were downloaded from NASA's web site for free (http://mirador.gsfc.nasa.gov/). Based on ArcGIS software, TRMM 3B43 precipitation rate $(\mathrm{mm} / \mathrm{h})$ was extracted from HDF files, and then multiplied by days per month to generate monthly precipitation raster data. 


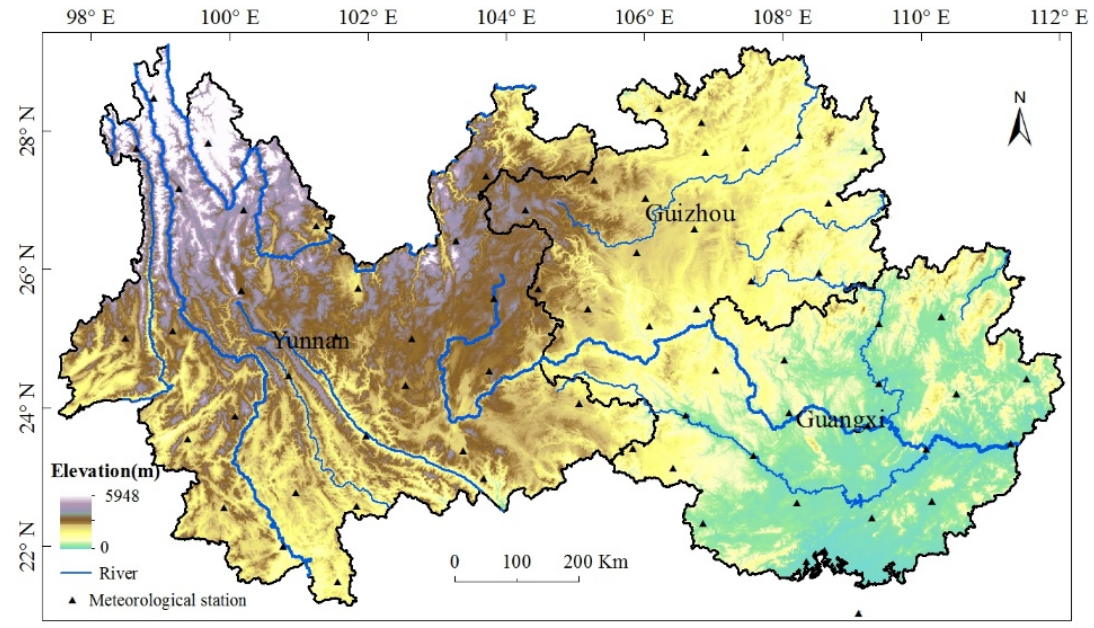

Figure 1. The Dian-Qian-Gui Karst areas and the distribution of meteorological stations

\subsection{Monthly Ground Climate Data}

The monthly ground climate data from 1998 to 2012 of DianQian-Gui Karst areas were obtained from China meteorological science data sharing service center (http://cdc.cma.gov.cn). This dataset contained several meteorological parameters, such as air pressure, temperature, humidity, wind direction, wind speed, precipitation, sunshine, et al. The monthly precipitation data were used to verify the applicability of TRMM 3B43 data in the research area. The total meteorological stations selected were 72, among which 23, 20 and 29 meteorological stations were in Guangxi, Guizhou and Yunnan provinces, respectively. (Figure 1).

\section{METHOD}

\subsection{Z INDEX}

$\mathrm{Z}$ index is closely related to the spatial and temporal distribution of precipitation, which can well describe the occurrence degree of single-site drought. Generally, the precipitation does not meet the normal distribution, so the Person- II precipitation distribution are put forward by some scholars to fit a certain period of time. By normalizing the precipitation, the Person-III distribution are transformed into standard normal distribution with $\mathrm{Z}$ index as a scalar. The formula of $Z$ index is as follows (Ju et al., 1997, 1998):

$$
\begin{aligned}
& Z_{i}=\frac{6}{C_{s}}\left(\frac{C_{s}}{2} \varphi_{i}+1\right)^{1 / 3}-\frac{6}{C_{s}}+\frac{C_{s}}{6} \\
& C_{s}=\sum_{i=1}^{n}\left(x_{i}-\bar{x}\right)^{3} / n \sigma^{3}, \varphi_{i}=\left(x_{i}-\bar{x}\right) / \sigma \\
& \sigma=\sqrt{\frac{1}{n} \sum_{i=1}^{n}\left(x_{i}-\bar{x}\right)^{2}}, \bar{x}=\frac{1}{n} \sum_{i=1}^{n} x_{i}
\end{aligned}
$$

Where $Z_{\mathrm{i}}=\mathrm{Z}$ index of the $i$ th month at a certain grid point $\mathrm{C}_{\mathrm{S}}=$ skewness coefficient $\varphi_{\mathrm{i}}=$ standard variable $\chi_{\mathrm{i}}=$ the $i$ th month at a grid point $\sigma=$ standard deviation

$-$ grid point

$x=$ average of precipitation sequence

$\mathrm{n}=$ sample number of precipitation sequence of the

In general, drought and flood level determined by $\mathrm{Z}$ index were divided into 7 grades: extreme flood, severe flood, partial flood, normal, partial drought, severe drought and extreme drought (Table 1).

\begin{tabular}{|c|c|c|}
\hline code & grades & Z Index \\
\hline 1 & extreme flood & $>1.645$ \\
2 & severe flood & $(1.037,1.645]$ \\
3 & partial flood & $(0.842,1.037]$ \\
4 & normal & $(-0.842,0.842]$ \\
5 & partial drought & {$[-1.037,-0.842)$} \\
6 & severe drought & {$[-1.645,-1.037)$} \\
7 & extreme drought & $<-1.645$ \\
\hline
\end{tabular}

Table1. Drought and flood grades determined by $\mathrm{Z}$ index

\section{RESULTS AND ANALYSIS}

\subsection{Accuracy evaluation of TRMM 3B43 precipitation data}

The monthly ground precipitation data of 72 meteorological stations from January 1998 to December 2012 in the research areas were selected to evaluate the accuracy of TRMM 3B43 precipitation data in the same period. It could be seen from Figure 2 that the precipitation data of TRMM 3B43 were highly consistent with the ground data of meteorological stations, but TRMM $3 \mathrm{~B} 43$ had an overestimation of precipitation in some periods. 


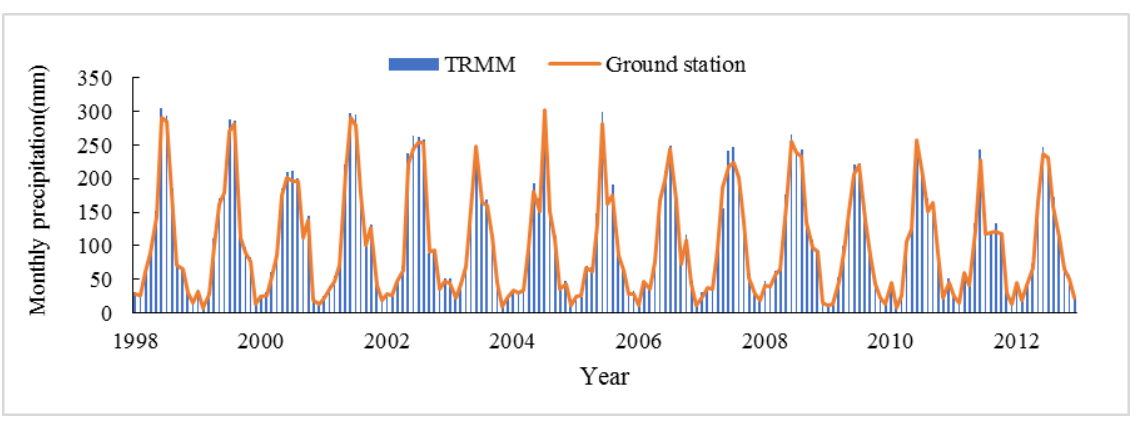

Figure 2. Inter-annual variation of monthly average precipitation of TRMM 3B43 compared with ground data

In order to further verify the accuracy of TRMM 3B43 precipitation data in the research area, parameters of correlation coefficient ( $r$ ) and relative Bias (Bias) were used for verification. Where, the closer the value of $r$ is to 1 , the better the data consistency; The closer the value of Bias is to zero, the more accurate the data. According to Figure 3, there was a significant positive correlation between TRMM 3B43 precipitation data and the ground meteorological stations on the monthly scale, with a correlation coefficient of 0.92 , which passed the significance test of 0.01 level, indicating TRMM 3B43 precipitation data had a good consistency with the ground meteorological stations. The calculated result of relative Bias was -0.058 , indicating that TRMM 3 B 43 precipitation was slightly higher than the ground precipitation.

It can be seen from Fig.4 that the correlation coefficient of more than $95 \%$ stations were greater than 0.9 , and the maximum value of the correlation coefficient was 0.98 , which located in no.9 Guizhou Xianning station, and the minimum value was 0.35 , which appeared in no.50 Guangxi Guilin station. In addition, in terms of the relative deviation, the absolute value of the relative deviation was between 0 and $20 \mathrm{~mm}$ accounted for $86 \%$ of the site. There were 4 stations with relative deviation greater than $30 \mathrm{~mm}$, which were Deqin station in Yunnan, Weizhou island station in Guangxi, Kunming station in Yunnan, and the site number were 1, 72, 12 and 15 respectively. In general, TRMM 3B43 precipitation data had a good correlation with the ground data, and could meet the study of regional precipitation variation characteristics at the monthly scale and above. It had a good applicability in the karst area of Yunnan, Guizhou and Guangxi.

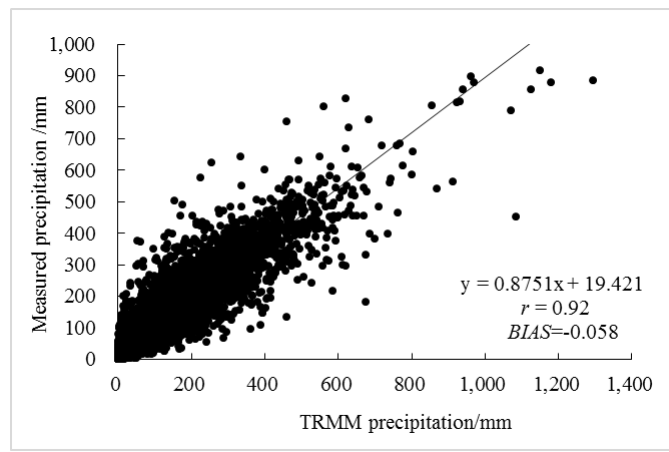

Figure 3. Scatter diagram of TRMM 3B43 monthly precipitation and ground data

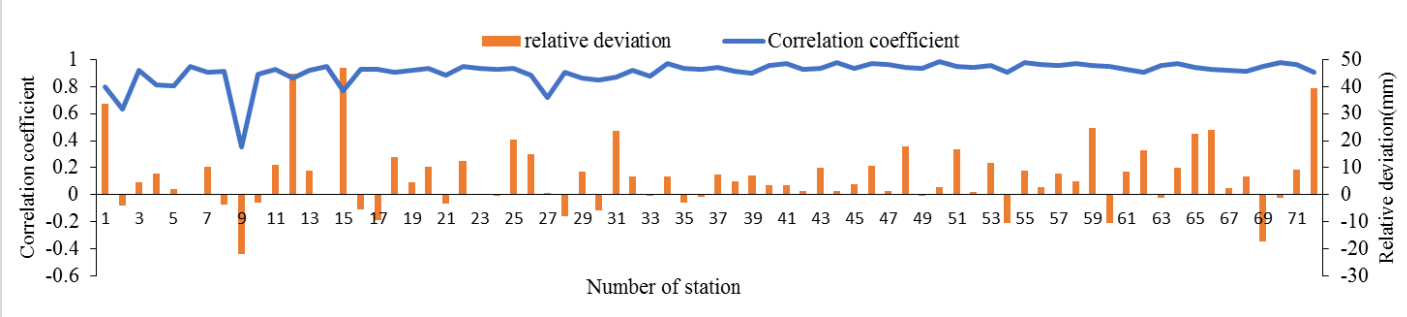

Figure 4. Correlation coefficient and relative deviation of TRMM 3B43 monthly precipitation and ground data

\section{2 spatial and temporal variations of precipitation}

The annual average monthly rainfall was calculated based on TRMM 3B43 precipitation data from 1998 to 2017. As could be seen from Figure 5, there were seasonal variations of precipitation, and rainy season was mainly distributed in spring and summer, while less rainfall in autumn and winter. This phenomenon was connected with the subtropical monsoon climate of the study area, which affect the seasonal distribution of rainfall. In summer, there are monsoons from the southeast of the Pacific Ocean and from the southwest of the Indian Ocean, which bring warm and humid air. With the movement of summer monsoon, Nanling area enters rainy season in May. Then the Yangtze River basin enters the plum rain season in June. Afterward, the north China and northeast China enter the rainy season. While, the monsoon from northwest of Mongolia and Siberia are prevailed in winter, which carry cold and dry air and the dry season comes. The rainy season ends in October.

Therefore, the rainy season began in May, and increased with the zone of rainfall moving. In May, the rainfall was between $100-350 \mathrm{~mm}$, and the rainfall was less than $100 \mathrm{~mm}$ in the north of Yunnan, and that was great than $300 \mathrm{~mm}$ in the east of Guangxi. In June, areas with rainfall less than $100 \mathrm{~mm}$ was shrank to the northern part of Yunnan, and that great than $300 \mathrm{~mm}$ was spread to the entire part of Guangxi and the north of Guizhou. In July, the area with rainfall less than $100 \mathrm{~m}$ moved to the north of Guizhou, and that great than $300 \mathrm{~m}$ were moved to the west of Yunnan and the south part of Guangxi. Then in August, the areas with rainfall great than $300 \mathrm{~mm}$ were shrank to the south and southeast of the study area. Since September, the rainfall decreased from northwest to southeast 
gradually. In October, the rainfall decreased less than $100 \mathrm{~mm}$ in most of the study area. The rainfall was less than $100 \mathrm{~mm}$ in the study area in November, and areas with rainfall less than $30 \mathrm{~mm}$ was spread from the north part of Yunnan to the east part of the entire area. In February, the areas with rainfall less than $30 \mathrm{~mm}$ researched the maximum. The situation had eased gradually since March

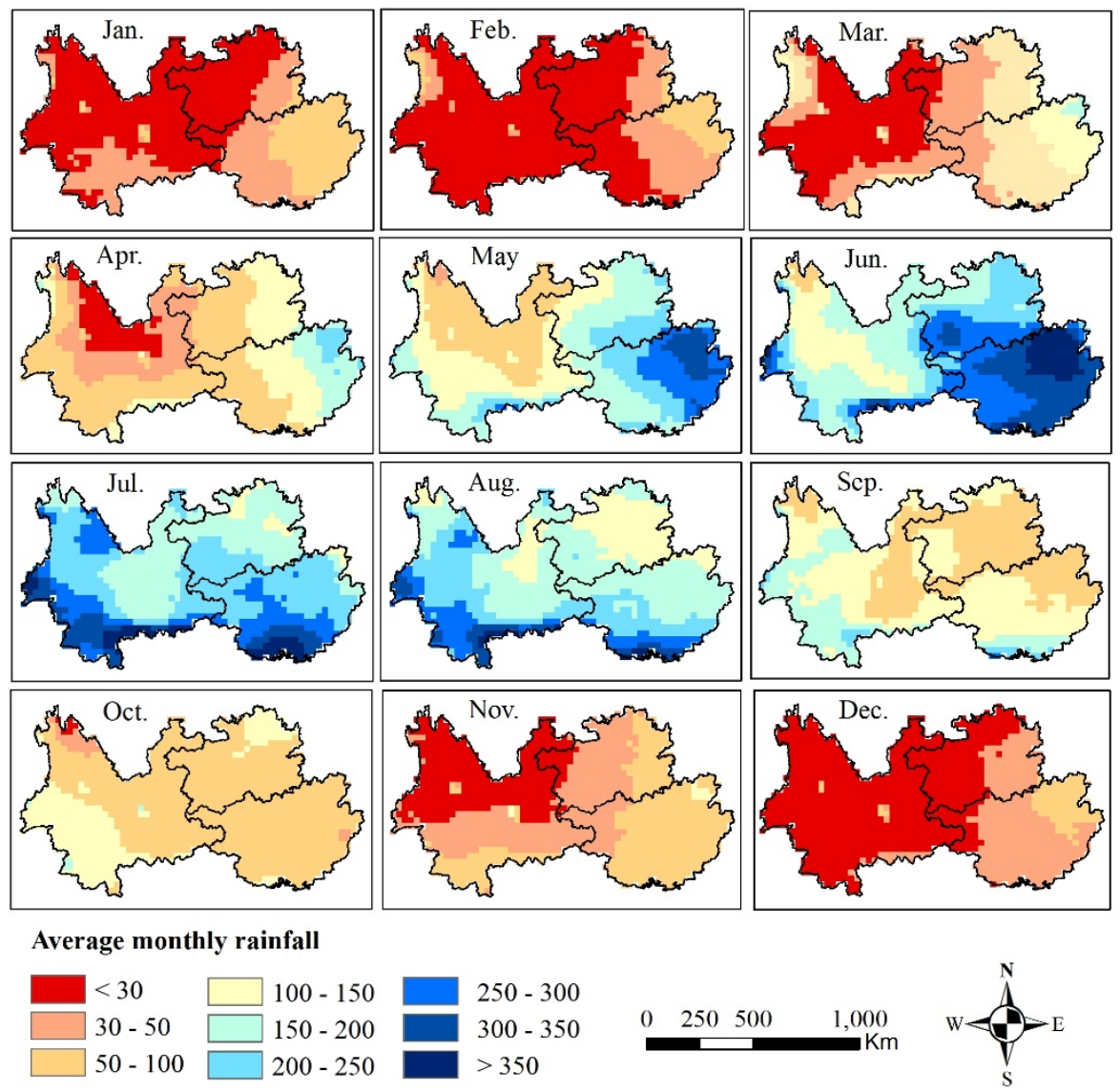

Figure 5. Annual average monthly rainfall

\subsection{Temporal characteristics of drought and flood}

Based on the TRMM 3B43 precipitation data, the $\mathrm{Z}$ index were calculated of Yunnan, Guizhou and Guangxi karst areas from 1998 to 2017 at the monthly scale. As could be seen from Figure 5, the $\mathrm{Z}$ index fluctuated between -1.160 and 1.678. In July 1999 , the $Z$ index reached the maximum value of 1.678 , indicating that the precipitation of this month increased the most compared with the mean value of the same period in the past 20 years, and the flood degree was the greatest. In February 2010, the $\mathrm{Z}$ index reached the minimum value of 1.160 , indicating that the precipitation of this month had the largest decrease compared with the mean of the same period in the past 20 years, and the drought was the worst.

According to the $\mathrm{Z}$ index, the drought grade from 1998 to 2017 at the monthly scale in the study area was illustrated in Figure 6. Based on the monitoring results of TRMM data in the past 20 years, it could be seen that drought and flood in the basin was mainly distributed in 6 grades, among which 153 months were normal, 47 months were flood (1 month extreme flood, 40 months severe flood, 6 months partial flood), and 40 months were drought months (27 months partial drought, 13 months severe drought).
In addition, in terms of the duration of drought and flood, there were 4 consecutive months of flood from May to August 2002, 3 consecutive months of flood from May to July 2001, and 3 consecutive months of flood from June to August in 2007, 2008 and 2017 respectively. There were three consecutive months of drought from December 2008 to February 2009. To sum up, flood mainly arose in summer with abundant rainfall, while drought mainly appeared in winter with less rainfall.

\subsection{Spatial pattern of drought and flood}

According to the grade and duration of drought and flood in Dian-Qian-Gui Karst Areas, typical examples were selected as to study the spatial variation characteristics and distribution pattern of drought and flood disasters in monthly scale from March of 2008 to January of 2009. On the basis of the $\mathrm{Z}$ index in the study period, the grades of drought and flood could be divided into five types.

Due to the influencing of monsoon climate and topography, the spatial characteristic of drought and flood had some difference in different months. As we could see from Figure7, flood month began in May, and ended in September. The time was consistent with the raining season. In May, partial areas occurred server to extreme flood, mainly distributed in the south of Guangxi and north of Guizhou. In June, the flood areas expanded to the entire of Guangxi and almost the total of 
Yunnan, and the flood areas moved to the west of Guizhou. The areas with extreme flood mainly distributed in Guangxi and partial area of Yunnan and Guizhou. Then in July, the flood areas covered almost the entire region of Yunnan and Guizhou and the Midwest of Guangxi, but the region with extreme flood moved to the middle of Yunnan and the northwest of Guangxi and the west of Guizhou. In August, the distribution of flood areas were similar as July, however the region with extreme flood changed to the middle of Guizhou, and the southwest of Guangxi, and south of Yunnan. In September, the flood eased in almost the study areas except the southwest of Guangxi. From October to November, almost areas were normal except severe drought in the southeast of Guangxi and northwest of Yunnan. But from December to February of the following year, there happened severe drought in the study areas. The area with severe drought accounted for
$58 \%, 61 \%$ and $62 \%$ of total study area in December of 2018 , January and February of 2019 respectively. But the spatial pattern of severe drought had some difference. In December of 2018, severe drought mainly distributed in the Mid-north of Guangxi, east of Guizhou, southeast and northwest of Yunnan. The severe drought areas expanded to the entire of Guangxi and southwest of Yunnan in January 2009. Then the severe drought areas shrank to north of Guizhou, and moved to Midsouth of Yunnan, and occupied almost entire of Guangxi in February of 2009.

From the above analysis, we could summary that the drought usually occurred in winter, while flood always happened in summer. And drought and flood were significant influenced by the monsoon climate.

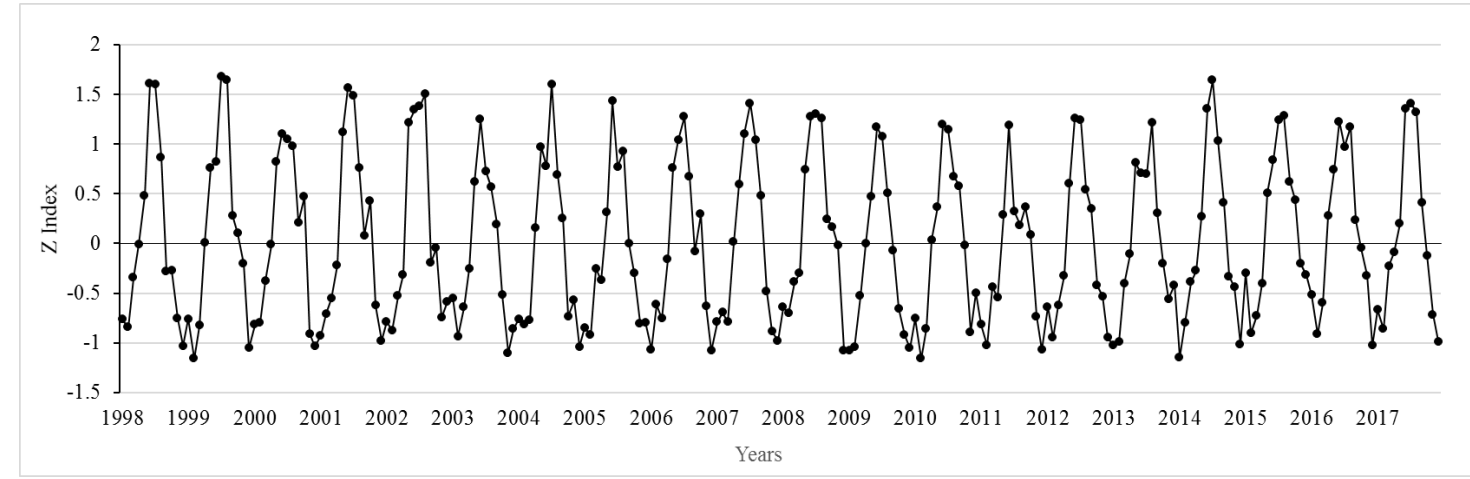

Figure 5. Monthly Z index from January 1998 to December 2017

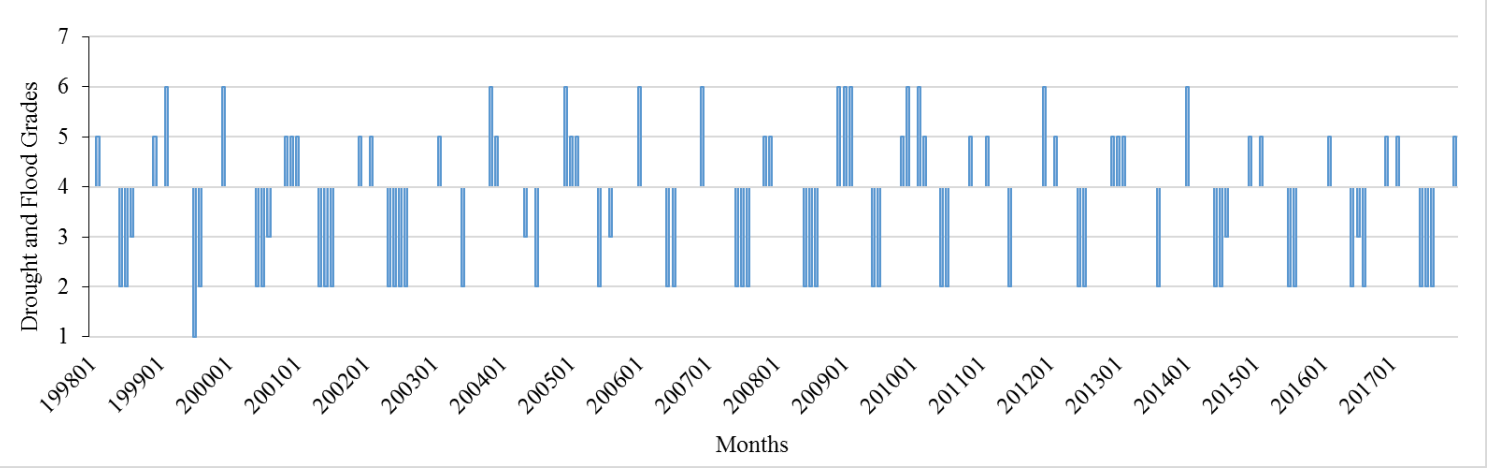

Figure 6. Monthly drought and flood grades from January 1998 to December 2017 


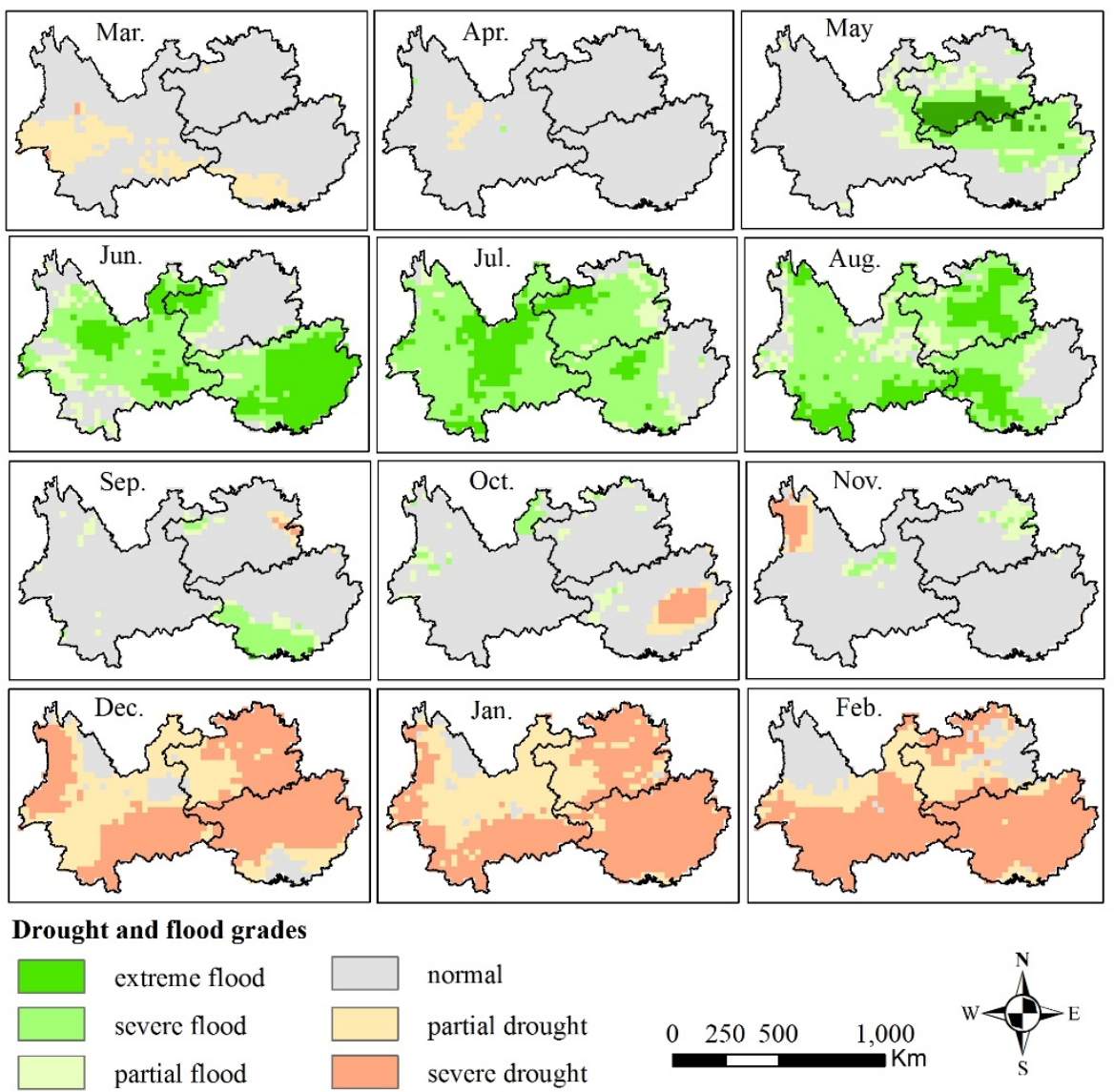

Figure 7. Evolution characteristics of drought and flood from March of 2008 to January of 2009

5. CONCLUSIONS

In this paper, we investigated the spatial and temporal evolution characteristics of drought and flood in the DIANQIAN-GUI karst areas based on TRMM-Z index during 19982017. The research may be helpful for the prevention of drought and flood disasters in the study area. Following conclusions could be made from our analysis:

1. TRMM 3B43 precipitation data had a good correlation with the ground data, and had a good applicability in the karst area of Yunnan, Guizhou and Guangxi.

2. There were seasonal variations of precipitation, and rainy season was mainly distributed in spring and summer, while less rainfall in autumn and winter. This phenomenon was greatly influenced by the subtropical monsoon climate. 3. According to the $\mathrm{Z}$ index, 153 months were normal, 47 months were flood, and 40 months were drought months in the study period. Take March of 2008 to January of 2009 as the typical example, the grades of drought and flood could be divided into five types according to the $Z$ index. We concluded that severe drought usually occurred in winter, while extreme flood always happened in summer

\section{ACKNOWLEDGEMENTS}

This research was financially supported by Guangxi Key Laboratory of Spatial Information and Geomatics (16-380-2508), Guangxi young and middle-aged teacher's basic ability improvement project (KY2016YB192).

\section{REFERENCE}

Ju,X.S., Yang,X.W., Chen,L.J., Wang,Y.M., 1997: Research on determination of station indexes and division of regional flood/drought grades in China. Quarterly Journal of Applied Meteorlolgy,8(1),26-33. ( in Chinese)

Ju,X.S., Zou,X.K.,Zang,Q., 1998: The method of the climatic drought flood index and its analysis,Journal of natural disasters, 7(3), 51-57. ( in Chinese)

Huang, R. H., Liu, Y., Wang, L., Wang, L., 2012: Analyses of the causes of severe drought occuring in Southwest China from the fall of 2009 to the spring of 2010. Chinese Journal of Atmospheric Science, 36 (3), 443-457.

He, J. Y., Zhang, M.J., Wang, P., Wang, S.J., Wang, X.M.,2011: Climate Characteristics of the Extreme Drought Events in Southwest China during Recent 50 Years, ACTA GEOGRAPHICA SINICA, 66 (9), 1179-1190. 
Hao, C., Zhang, J. H., Yao, F.M., 2015. Combination of multisensor remote sensing data for drought monitoring over southwest china. International Journal of Applied Earth Observation and Geoinformation, 35, 270-283.

Huang, W.H., Yang, X.G., Li, M.S., Zhang, X.Y., Wang, M.T.,Dai,S.W., Ma,J.H., 2010. Evolution characteristics of seasonal drought in the south of china during the past 58 years based on standardized precipitation index. Transactions of the Chinese Society of Agricultural Engineering, 26(7), 50-59. (in Chinese)

He,M., Song,L.S., Wang, Z.P.,Gu,Q., Wang, D.J., Guo, B., 2018.

Evaluation of Drought Monitoring Indices Based on Multisource Data in Southwest China. Journal of Natural Resources, 33(7), 1257-1269. ( in Chinese)

Liu, B.J., Chen, C.L., Lian, Y.Q., Chen, J.F., Chen, X. H., 2015 Long-term change of wet and dry climatic conditions in the southwest karst area of china. Global and Planetary Change, $127,1-11$.

Li,Y.J., Ren,F.M., Li,Y.P., Wang,P.L., Yan,H.M., 2014. Characteristics of the regional meteorological drought events in southwest china during 1960-2010. Journal of Meteorological Research, 28(3), 381-392.
Li,X., He,B.B., Quan, X.W., Liao, Z.M., Bai,X.J., 2015. Use of the Standardized Precipitation Evapotranspiration Index (SPEI) to Characterize the Drying Trend in Southwest China from 1982-2012. Remote Sensing,7,10917-10937

Wang, Z.L., Li, J., Lai, C.G., Huang, Z.Q., Zhong, R.D., Zeng, Z.Y., Chen, X. H., 2017. Increasing drought has been observed by SPEI_pm in Southwest China during 1962-2012. Theoretical and Applied Climatolog. doi: 10.1007/s00704-0172152-3.

Wu, X.S., Wang, Z.L., Zhou, X.W., Lai, C. G., Lin, W.X., Chen, X.H., 2016. Observed changes in precipitation extremes across 11 basins in china during 1961-2013. International Journal of Climatology, 36(8), 2866-2885.

Yang, J., Gong, D.Y., Wang, W.S., Hu, M., Mao, R., 2012. Extreme drought event of 2009/2010 over Southwestern China. Meteorology and Atmospheric Physics, 115(3-4), 173-184.

Yang, J.H., Zhang, Q.,Wang, J.S.,Yao, Y.B., Shang,J.L., 2015. Extreme and Persistent Feature of Drought and Flood of Southwest China in Past 60 Years. SCIENTIA GEOGRAPHICA SINICA, 35(10),1333-1340.( in Chinese) 